\title{
Brucellosis Presented as Thyroiditis: A Rare Case Report
}

\author{
Mahsa Alinaghian 1*, Majid Avijgan² \\ ${ }^{1}$ Department of Infectious Diseases, Isfahan University of Medical Sciences, Isfahan, Iran \\ ${ }^{2}$ Departments of Traditional Persian Medicine and Infectious Diseases, Isfahan University of Medical Sciences, Isfahan, Iran \\ Email: *avijgan@yahoo.com
}

How to cite this paper: Alinaghian, M. and Avijgan, M. (2016) Brucellosis Presented as Thyroiditis: A Rare Case Report. Advances in Infectious Diseases, 6, 157-162. http://dx.doi.org/10.4236/aid.2016.64019

Received: November 7, 2016

Accepted: December 2, 2016

Published: December 5, 2016

Copyright $\odot 2016$ by authors and Scientific Research Publishing Inc. This work is licensed under the Creative Commons Attribution International License (CC BY 4.0).

http://creativecommons.org/licenses/by/4.0/

\begin{abstract}
Brucellosis is an endemic zoonotic disease around the world such as Iraq, Turkey, and Iran. Brucella is brought into attention by affecting various organs thorough complications, but thyroiditis is a rare one. Here, we present a case of Brucellosis with neck discomfort and odynophagia who developed thyroiditis and was treated by antibiotic and corticosteroid therapy. This case report aims to draw clinicians' attention to thyroiditis as a rare complication of brucellosis.
\end{abstract}

\section{Keywords}

Brucellosis, Thyroiditis, Corticosteroid Therapy

\section{Introduction}

Brucellosis is a zoonotic gram negative bacterium which causes health issues around the globe considerably Mediterranean areas [1] [2]. It is still endemic in some areas in Iran among shepherds and ranchers [3] [4]. The most common strains of bacteria are Brucella melitnensis and Brucella abortus [2] [5]. Humans are contaminated by brucella bacteria through digestive pathway, skin wounds, and inhalation during contact with infected domestic animals. A usual manner of illness is through usage of non-pasteurized dairy [6] [7]. Patients show symptoms of fever, malaise, fatigue, weight loss, and headache. Fever of unknown origin (FUO) is the most documented symptom in these patients; however, it can be misdiagnosed with malignancies and other infections. Brucellosis is a multi-organ illness which causes infertility and abortion in domestic animals. Moreover, brucellosis has impact on cardiovascular system, neurological system, respiratory system, and gastrointestinal system [7] [8]. So, it is necessary to diagnose and treat brucellosis before the complications overcome. Failure to do so will result in mor- 
bidities far too devastating to recover from such as spondylitis. The most common site of complications is musculoskeletal system which presents itself as severe back pain and sacro-ileitis [4] [5] [7] [9] [10]. On the other hand, few cases of thyroiditis are reported as a result of human brucellosis [2] [11] [12]; Nonetheless, less than $1 \%$ of surgically treated suppurative thyroiditis is because of Brucella [1] [11]. Hereon, we report a case of female rancher who complained of neck pain and describe the obstacles we faced during our course of diagnosis and treatment.

\section{Case Presentation}

A 62-year-old female rancher was referred to our Emergency Department with odynophagia and high fever. The intermittent fever (FUO) had started gradually 20 days before her recent admission. She had been hospitalized in another center because of fever of unknown origin 2 weeks ago. Base on her initial $2 \mathrm{ME}=1 / 80$ and Wright test $=1 / 160$, Cefteriaxone and Doxycycline had been administered. Unfortunately, she had left the treatment unfinished because of her own request and lack of cooperation. At the time of her presence in our department, she complained of neck discomfort, chills, malaise, unusual perspiration, sore throat, and odynophagia. Moreover, she had suffered from considerable weight loss during this period and had no recent productive cough or urinary symptoms. As a matter of fact, she was used to consuming unpasteurized dairy products.

During physical examination, she had an enlarged tender nodular thyroid gland (Figure 1). Lab analysis revealed the following data: low TSH: $0.24 \mathrm{uIU} / \mathrm{ml}(0.4-0.7)$, high free T4: $10.7 \mathrm{ng} / \mathrm{dl}(0.8$ - 2.8), T3: $108 \mathrm{ng} / \mathrm{dl}$ (84 - 170), T3 uptake: $28.2 \mathrm{md} / \mathrm{dl}$ (24 35.5), Cr: $0.8 \mathrm{mg} / \mathrm{dl}$, Brucella IgM: 0.59 (Negative < 0.8 Ratio), Brucella IgG: 153 (Negative < $16 \mathrm{RU}$ ), Wright: 1:1280, and 2ME: 1:1280. Interestingly, Brucella was detected in her BACTEC blood culture as well.

Ultrasonography revealed bilateral asymmetric enlarged thyroid gland. Right and left thyroid lobes had a diameter of $38 \times 24 \times 26 \mathrm{~mm}$ and $42 \times 38 \times 37 \mathrm{~mm}$ respectively

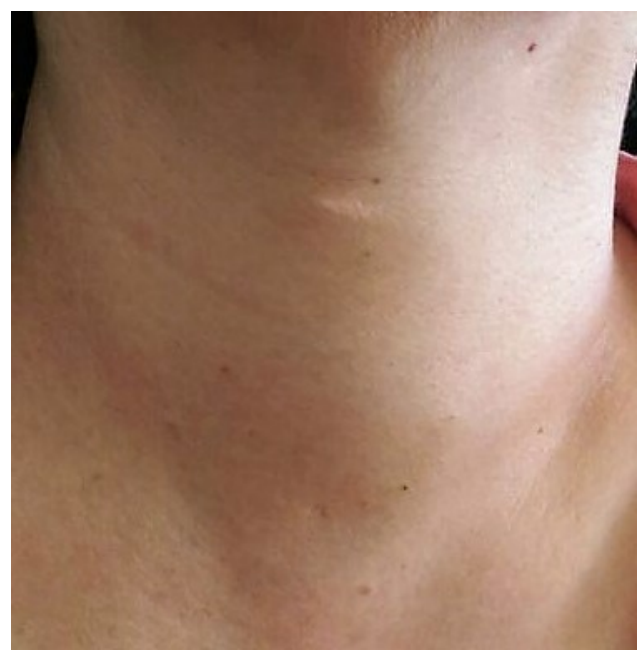

Figure 1. Thyromegaly in our case. 


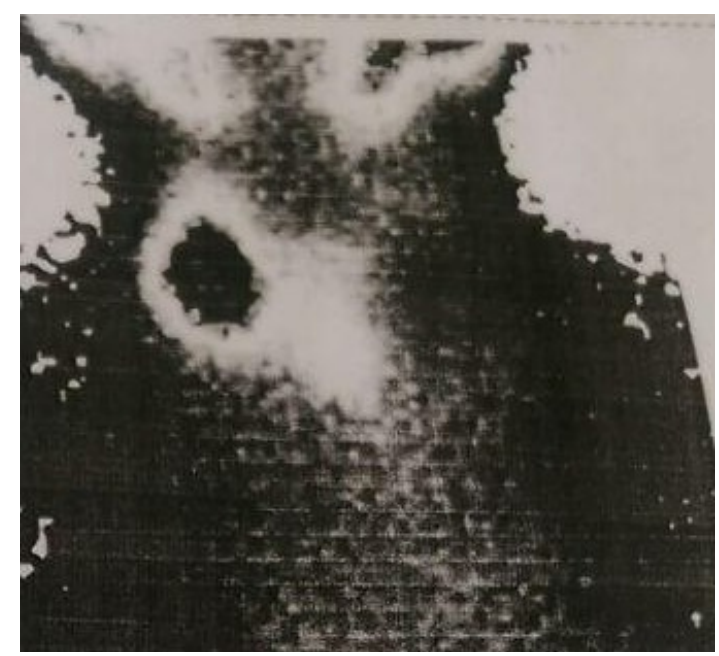

Figure 2. Thyroid Scan shows functional nodule in the right lobe.

with reduced parenchymal echo. Multiple round thick-walled nodules with echo-free centers and peripheral vascular flow were detected in the right lobe. Moreover, a cystic lobulated colloidal nodule with the diameter of $37 \times 34$ was observed on the left lobe. Also, several cervical enlarged lymph nodes with high vascular flow were found. Overall, neck ultrasonography represented an inflammatory process. Thyroid scan detected a large cold mass in the left lobe and several functional nodules in the right lobe (Figure 2). In order to rule out abscess formation, fine needle aspiration (FNA) was done which showed inflammatory blood elements such as neutrophils and macrophages in a field of thyroid follicular cells. Final pathological evaluation of FNA documented cystic degeneration in accordance with adenomatous goiter without abscess formation.

Based on our clinical evaluation, the patient had been treated by Tetracycline $2 \mathrm{gr}$ daily, Rifampin 300 twice daily, and Streptomycin 500 daily for 14 days. Our endocrinologist advised corticosteroid therapy in case of thyroiditis. So, oral Prednisolone 50 $\mathrm{mg}$ has been administered daily during her hospitalization which had been tapered over 2 weeks after discharge. She was symptom free when she left the hospital. She received Tetracycline $2 \mathrm{gr}$ and Rifampin $600 \mathrm{mg}$ daily for 3 months after her discharge. On follow-up after 4 months, she had normal thyroid function tests and no clinical complaints.

\section{Discussion}

Brucellosis is a well-known health problem in endemic regions such as Iran [3] [7] [13] which can lead to severe disability if it is ignored. Studies claim that virtually all human organs are at risk of Brucella infection and future complications [1] [2] [14]. Age and gender are not protective factors against brucellosis, however, some complications such as thyroiditis are more common among females [7] [11] [15]. Thyroid gland defense mechanism includes high blood flow, iodine content, and various lymphatic drainages in the neck [11] [12]. Also, it is separated from other structures by neck fascia. Despite the fact that various theories are presented, Brucella bacteria is transmitted through 
blood to the thyroid gland [1] [12]. So, thyroid bacterial infection is rare and abscess formation is expected when it is left untreated. The first thyroiditis due to brucellosis was documented in 1989 in a Bengali shepherd. Recent case studies have reported involvement of thyroid gland by Brucella [1] [2] [11] [12] [16] [17], although bone and joint are mostly affected by it complications. Often, misdiagnosis happens because the most common symptom is fever of unknown origin (FUO) [6] [15] [18]. Regarding this complication, enlarged thyroid gland presents itself by neck discomfort, difficult swallowing, and dyspnea [1]. Unspecific documented clinical symptoms are fever, insomnia, arthralgia, anorexia, weight loss, night sweating, and headache [8] [13]. So, further radiological investigation is necessary to evaluate thyroid abscess in these cases. Ultrasonography is the method of choice although MRI clearly explores the neck structure and its relation to abscess formation. However, thyroid scan may show normal or cold function [11]. Few studies have reported brucella thyroiditis and suggest to consider it in endemic areas when patients complain of thyromegaly and neck discomfort [2] [11] [12] [16] [17]. The gold standard method in diagnosing brucellosis is blood culture, however, sensitivity is low among chronic cases. So, diagnosis is conducted with serological tests globally [5]. Studies found no statistical association between serological findings and positive blood culture, although it is advised to use PCR or blood culture in case of negative serological result [5] [18]. During the acute phase, IgM antibodies dominate the result [3] [18] [19]. Regarding the chronic phase, SATs are negative or show low titers, in contrast to SAT, other tests such as Coombs wright, immunodiffusion tests and immune-electrophoresis can be positive. It is reported that a negative $2 \mathrm{ME}$ test is highly suggestive of chronic phase [13] [19]. Furthermore, one seroprevalence study revealed that positive titer of SAT or Coombs with negative 2ME may suggest inactive or previous disease. [19] SAT titer more than 1:320 and titer 2-mercoptoetanol (2ME) more than 1:160 are considered positive Brucella infection in endemic areas [3] [8] [13] [15]. However, low levels of IgM antibody may be detectable in healthy individuals [19]. Thus, comparing serological findings to patients' clinical presentation is essential in making a proper decision. Brucella is an intracellular pathogen which makes choosing the right treatment plan crucial [13] [15] [18] [20]. Treatment regimen is based on the patient, phase of the disease, and its severity. Treatment scheme is a combination of doxycycline and aminoglycosides or rifampicin for 6 weeks. In case of Brucella complications, triple therapy and extended treatment duration are suggested [18] [20]. Some studies claim that a course of interamuscular gentamycin and doxycycline has the same efficacy as doxycycline and streptomycin combination [18]. In contrast, a study showed that doxycycline and streptomycin was more preferred than combination of doxycycline and rifampicin [20]. According to our case, we used triple antibiotic regimen and a course of corticosteroid for 14 days which was followed by Tetracycline plus Rifampin regimen for 3 months after discharge.

\section{Conclusion}

In conclusion, it is advised to consider brucellosis as a differential diagnosis of patients 
with thyroid mass in endemic areas. Furthermore, radiological investigation is suggested to detect thyroid abscess formation because of Brucella secondary infection. Although serological findings play a critical role in diagnosis, imaging is necessary during investigation of thyroiditis among thyromegaly cases in endemic areas. Also, longer course of treatment and triple antibiotic regimen is suggested in these cases to prevent treatment failure and future relapse.

\section{References}

[1] Rohondia, O., Koti, R., Majumdar, P., Vijaykumar, T. and Bapat, R. (1995) Thyroid Abscess. Journal of Postgraduate Medicine, 41, 52-54.

[2] Vermiglio, F., Stassi, G., Finocchiaro, M.D. and Trimarchi, F. (1995) Thyroiditis Due to Brucella Melitensis. Journal of Endocrinological Investigation, 18, 308-310. https://doi.org/10.1007/BF03347819

[3] Avijgan, M., Bakhsh, H.T., Ahmadi, F. and Khani, M.M. (1988) Seroprevalance of Brucellosis and Comparison of Brucellosis Serologic Tests in Shahr-e-Kord, Iran. Journal of Hakim, $1,37-45$.

[4] Avijgan, M. (1999) Sacro-Ileitis, the Common Presentation of Brucellosis. Journal of Shahrekord University of Medical Sciences (JSKUMS), 1, 6-12.

[5] Asadi, F.T., Hashemi, S.H., Alikhani, M.Y., Moghimbeigi, A. and Naseri, Z. (2016) Clinical and Diagnostic Aspects of Brucellosis and Antimicrobial Susceptibility of Brucella Isolates in Hamedan, Iran. Japanese Journal of Infectious Diseases. https://doi.org/10.7883/yoken.JJID.2016.133

[6] Avijgan, M., Avijgan, M., Najafi, M.R., Salek, N., Momeni, A., Shabani, S., et al. (2015) Integrative Medicine and Drug-Induced Vestibulopathy Following Brucellosis Treatment: Clinical Practice. Integrative Medicine International, 1, 176-184. https://doi.org/10.1159/000371800

[7] Hasanjani Roushan, M.R., Ebrahimpour, S. and Moulana, Z. (2016) Different Clinical Presentations of Brucellosis. Jundishapur Journal of Microbiology, 9, e33765. https://doi.org/10.5812/jjm.33765

[8] Mangalgi, S.S., Sajjan, A.G., Mohite, S.T. and Gajul, S. (2016) Brucellosis in Occupationally Exposed Groups. Journal of Clinical and Diagnostic Research, 10, DC24-DC27. https://doi.org/10.7860/jcdr/2016/15276.7673

[9] Avijgan, M. (2003) Skin Traction: A New Idea for Pain Management in Sacro-Ileitis of Brucellosis. Journal of Shahrekord University of Medical Sciences (JSKUMS), 2, 27-34.

[10] Tsimichodimos, V.A., Milionis, H.J., Metafrantzi, Z. and Elisaf, M.S. (2002) Severe Low Back Pain Due to Brucella Spondylitis. Infectious Diseases in Clinical Practice, 11, 437-440. https://doi.org/10.1097/01.idc.0000086408.30743.d6

[11] Akdemir, Z., Karaman, E., Akdeniz, H., Alptekin, C. and Arslan, H. (2015) Giant Thyroid Abscess Related to Postpartum Brucella Infection. Case Reports in Infectious Diseases, 2015, Article ID: 646209. https://doi.org/10.1155/2015/646209

[12] Sirmatel, F. and Akarsu, E. (2004) Case Report: A Brucellosis Case with Subacute Thyroiditis. Mikrobiyoloji Bulteni, 38, 149-153.

[13] Avijgan, M., Hafizi, M., Salemi, A. and Dehkordi, S.I. (2009) Unusual Presentation of Brucellosis: Afebrile, Culture Positive Brucellosis and Culture Positive, Seronegative Brucellosis. Asian Pacific Journal of Tropical Medicine, 2, 22-27.

[14] Avijgan, M., Karimi, I., Javadi, A. and Izadi, M. (2005) Brucellosis Arthritis: Infection or In- 
flammation of Joint? Zahedan Journal of Research in Medical Sciences (Tabib-E-Shargh), 7, 63-68.

[15] Kazak, E., Akalin, H., Yilmaz, E., Heper, Y., Mistik, R., Sinirtas, M., et al. (2015) Brucellosis: A Retrospective Evaluation of 164 Cases. Singapore Medical Journal, 57, 624-629.

[16] Von Graevenitz, A. and Colla, F. (1990) Thyroiditis Due to Brucella Melitensis-Report of Two Cases. Infection, 18, 179-180. https://doi.org/10.1007/BF01642110

[17] Acar, A., Turhan, V., Diktas, H., Oncul, O. and Cavuslu, S. (2009) [A Case of Brucellosis Complicated with Endocarditis, Pyelonephritis, Sacroileitis and Thyroiditis]. Mikrobiyoloji Bulteni, 43, 141-145.

[18] Hasanain, A., Mahdy, R., Mohamed, A. and Ali, M. (2016) A Randomized, Comparative Study of Dual Therapy (Doxycycline-Rifampin) versus Triple Therapy (Doxycycline-Rifampin-Levofloxacin) for Treating Acute/Subacute Brucellosis. The Brazilian Journal of Infectious Diseases, 20, 250-254. https://doi.org/10.1016/j.bjid.2016.02.004

[19] Pabuccuoglu, O., Ecemis, T., El, S., Coskun, A. and Akcali, S. and Sanlidag, T. (2011) Evaluation of Serological Tests for Diagnosis of Brucellosis. Japanese Journal of Infectious Diseases, 64, 272-276.

[20] Yousefi-Nooraie, R., Mortaz-Hejri, S., Mehrani, M. and Sadeghipour, P. (2012) Antibiotics for Treating Human Brucellosis. Cochrane Database of Systematic Reviews, 10, CD007179. https://doi.org/10.1002/14651858.cd007179.pub2

Submit or recommend next manuscript to SCIRP and we will provide best service for you:

Accepting pre-submission inquiries through Email, Facebook, LinkedIn, Twitter, etc. A wide selection of journals (inclusive of 9 subjects, more than 200 journals)

Providing 24-hour high-quality service

User-friendly online submission system

Fair and swift peer-review system

Efficient typesetting and proofreading procedure

Display of the result of downloads and visits, as well as the number of cited articles

Maximum dissemination of your research work

Submit your manuscript at: http://papersubmission.scirp.org/

Or contact aid@scirp.org 